\title{
EFFECT OF SALBUTAMOL ON THE PAROTID SALIVARY GLAND OF RATS: ULTRASTRUCTURAL STUDY
}

\author{
Mazen Abou Elkhier*, Samah Elmeadawy ${ }^{* *}$ and Naglaa Salama***
}

\begin{abstract}
Background: Salbutamol (salb) is a selective $\beta 2$-adrenergic receptor agonist used for the asthma to relieve bronchospasm. Because of the presence of $\beta 2$-adrenoceptors in salivary glands, salbutamol may have an effect on salivary composition. This study was carried out to evaluate the effect of Salbutamol on ultrastucture of parotid glands.

Materials and Methods: Study group (15 male albino rat) treated with injections of salb, while the control group (15 male albino rat) received saline. Rats were sacrificed at periods of 2 and 7 days of treatment and then one week after stoppage of treatment. The parotid was dissected and processed for transmission electron microscopy.
\end{abstract}

Results: after 2 days, acinar cells of the salb treated glands showed cytoplasmic vacuolization, granules of different electron densities with few electron dense bodies and rough endoplasmic reticulum (RER) with irregularly arranged cisternae. Dense areas of chromatin were observed at the periphery of the nucleus. After 7 days of salb treatment, the nucleus was compressed toward the base of the cell. One week after stoppage of salb, some cytoplasmic alterations still present.

Conclusion: short term treatment with salb drug leads to ultrastructural changes of the parotid and some of these changes still present after one week from cessation of the drug.

KEY WORDS: Salbutamol, Parotid gland, Electron microscopy

\section{INTRODUCTION}

Asthma is at once one of the most frequent chronic diseases in developed countries. It is characterized by reversible airway obstruction, hyper-responsiveness, and inflammation. The structural changes of the airway of asthma include fibrosis of subepithelial layer, hyperplasia of goblet cell, and hypertrophy of airway smooth muscle (1). Previously, however, non selective adrenergic agonists, such as inhaled epinephrine, have been used to relieve asthmatic bronchoconstriction (2), they are not recommended due to their excessive cardiac stimulation $^{(3)}$.

* Associate Professor of Oral Biology, Department of Oral Biology, Faculty of Dentistry, Mansoura University.

** Associate Professor of Oral Medicine and Periodontology, Department of Oral Medicine \& Periodontology, Faculty of Dentistry, Mansoura University.

***Associate Professor of Oral Pathology, Department of Oral Pathology, Faculty of Dentistry, Mansoura University. 
Nowadays, bronchoconstriction in asthma is commonly alleviated with $\beta_{2}$-agonists such as Salbutamol (salb), and formoterol. But, it was found that their over-use is associated with side effects ${ }^{(4)}$.

Many types of receptors, including $B$ adrenoceptors exist in salivary gland tissues, suggesting that salivary glands may contain target systems for many drugs like $\beta$ - receptor drugs (5). Parasympathetic stimulation of salivary gland acting on muscarinic-cholinergic receptors increase water and electrolyte secretion while sympathetic stimulation, acting through $\beta$-adrenergic receptors $(\beta-A R)$ increase protein synthesis and secretion ${ }^{(6)}$.

Systemic use of isoproterenol in rat leads to salivary gland enlargement that is preceded by massive protein secretion ${ }^{(7)}$. This glandular enlargement is caused by hyperplasia (increased numbers of acinar cells) and hypertrophy (increased size of acinar cells) ${ }^{(8)}$. The cellular changes associated with salivary gland enlargement include DNA synthesis ${ }^{(9)}$, an increase in glandular protein synthesis ${ }^{(10)}$, and differential changes in RNA transcription, with upregulated proline-rich protein (PRP) gene and downregulated amylase gene ${ }^{(11)}$.

However, the effects of non selective $\beta$-adrenergic agonists have been studied extensively in rodents, the ultrastructural cellular effects of the selective $\beta 1$ and $\beta 2$ agonists have been much less studied. The aim of this study was to evaluate the effect of Salb on the ultrastucture of the parotid salivary glands.

\section{MATERIAL AND METHODS}

All experiment study was done in Mansoura experimental research center(MERC) according to an ethical committee of Faculty of Dentistry, Mansoura University with code number (18060218). Thirty male, white albino rats weighing approximately 200 to $250 \mathrm{~g}$ were kept under laboratory conditions. The animals were acclimatized for 2 weeks before starting the study and then divided into two groups. The first group (control group), consisted of fifteen rats and given saline solution. The second group (study group) consisted of fifteen rats and received salb treatment.

\section{Drug administration:}

The saline and Salb were administered by the intraperitoneal route. The rats of the study group were given Salb in a dose of $4 \mathrm{mg} / \mathrm{kg}$ body weight (Ventolin, GlaxoSmithKlein, Brentford, United Kingdom) daily ${ }^{(12)}$. The rats in the control group were given equivalent volumes of saline. The treatment periods were continued for 7 days ${ }^{(13)}$.

Five rats of both control and study groups were randomly chosen and sacrificed by thiopental at periods of 2 and 7 days. The remaining animals were sacrificed at one week after the end of the treatment period. In preparation for examination by transmission electron microscopy (TEM), Collected tissue was immersed and fixed in $2.5 \%$ glutaraldehyde and post-fixed with $1 \%$ osmium tetroxide. After ethanol dehydration, samples were embedded in resin. Slices $(90-100 \mathrm{~nm})$ were prepared, and after staining with uranyl acetate and lead citrate, were examined with a transmission electron microscope.

\section{RESULTS}

\section{Transmission electron microscopy:}

\section{Control group:}

No differences were observed in the control group at different periods. The cytoplasm was filled with granules of different shapes. The rough endoplasmic reticulum (RER) and large mitochondria were surrounded by secretory granules. The granular endoplasmic reticula were rectangular and dense. Numerous microvilli were present in the lumen of the intracellular canaliculi. The mitochondria were of various sizes and morphology, but maintained the parallel aspect of the outer membrane. Uniformly dispersed chromatin was observed. An empty 


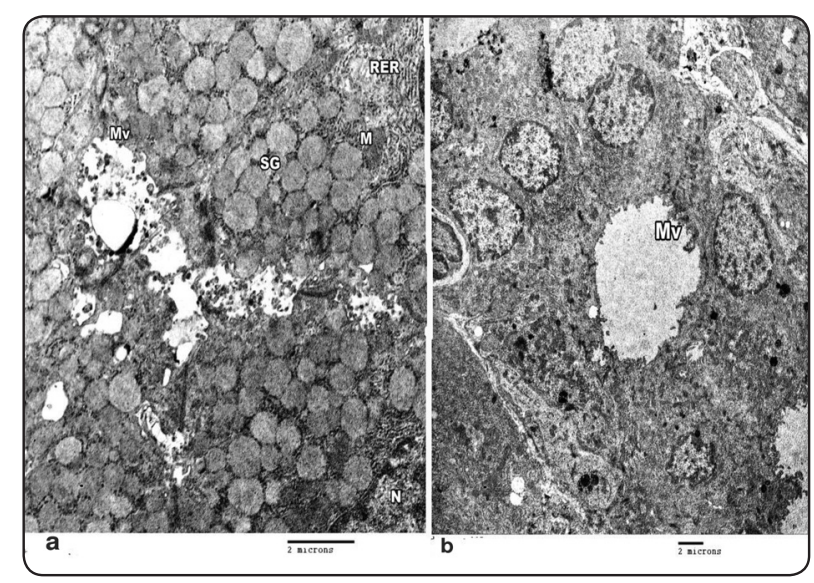

Fig. (1) (a) TEM of control shows rough endoplasmic reticulum (RER) with irregular condensed aspect, secretory granules (SG) filling the cytoplasm, microvilli (Mv) in the lumen, mitochondria (M), and part of the nucleus (N). (b) TEM of control shows an empty striated duct with microvilli (Mv).

striated duct with short microvilli in the apical membrane of the cells (the gland produced secretion spontaneously) (fig. 1).

\section{Salbutamol treated group:}

In the ultrastructural analysis, the acinar cells of the salb treated parotid glands at 2 days showed various alterations in the cytoplasmic organelles. Rough endoplasmic reticulum (RER) presented some expanded portions with cisternae arranged irregularly. The cytoplasm contained granules of different electron densities and a few of them have an electron dense body. Cytoplasmic vacuolization was observed. Intramitochondrial vacuolization was observed. Dense areas of chromatin were observed at the periphery of the nucleus. The lumen of the acini contained abundant microvilli and secretory materials (fig. 2).

At 7 days after salb treatment, there were expanded and irregular RER and different sizes, shapes and densities of secretory granules with some granules have dense core materials. The nucleus was compressed toward the base of the cell (fig. 3).
One week after stoppage of salb treatment, some cytoplasmic alterations still present. RER showed some expanded cisternae and dense bodies still seen inside some secretory vesicles. Some vacuoles were seen in the cytoplasm and variations in the maturation of secretory granules (fig. 4).

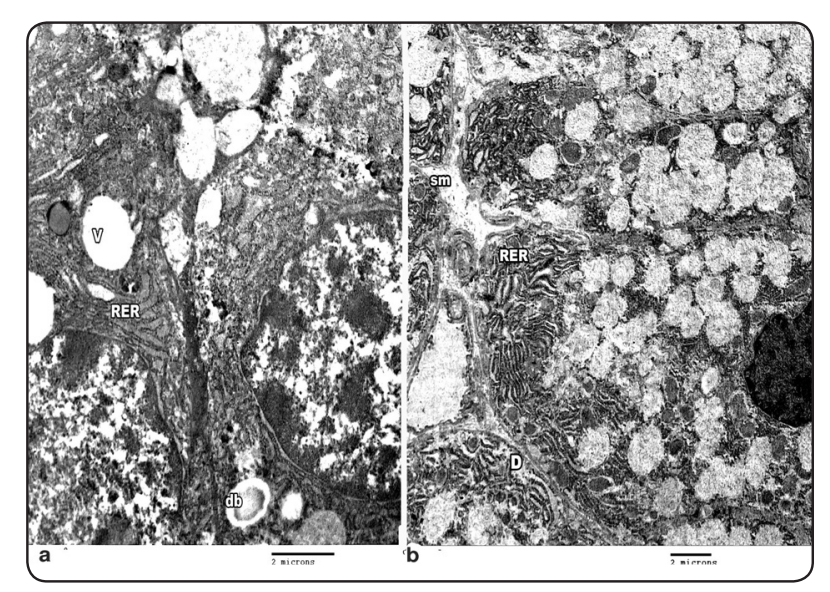

Fig. (2) (a) TEM of salbutamol treated group at 2 days shows dilated rough endoplasmic reticulum (RER), electron dense bodies within the secretory granules $(\mathrm{db})$, vacuoles (V) within the cytoplasm, and destructed mitochondria (M).(b)TEM of salbutamol treated group at 2 days shows dilated RER, secretory materials $(\mathrm{Sm})$ within the lumen, and intact desmosomal connection (D).

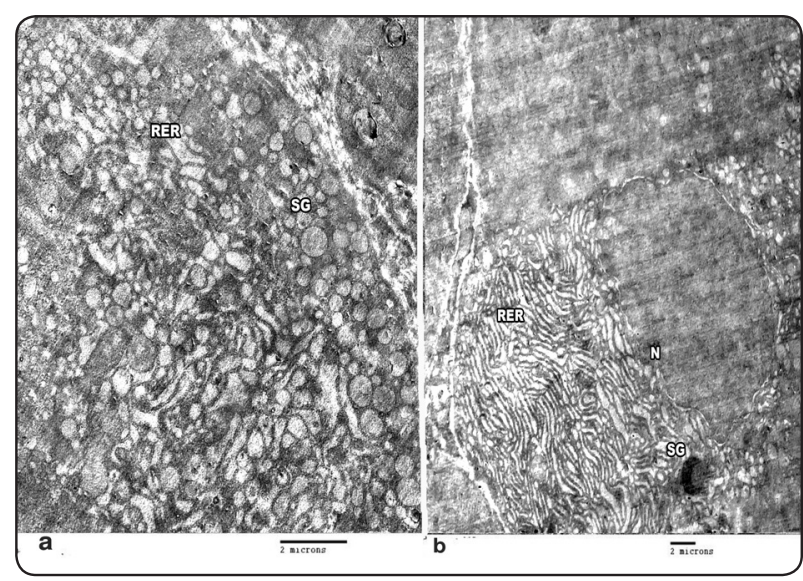

Fig. (3) (a): TEM of salbutamol treated group at 7 days shows dilated rough endoplasmic reticulum (RER), and different sizes of secretory granules (SG).(b): TEM of salbutamol treated group at 7 days shows irregular expanded rough endoplasmic reticulum (RER), some secretory granules contain dense materials, and compressed nucleus. 


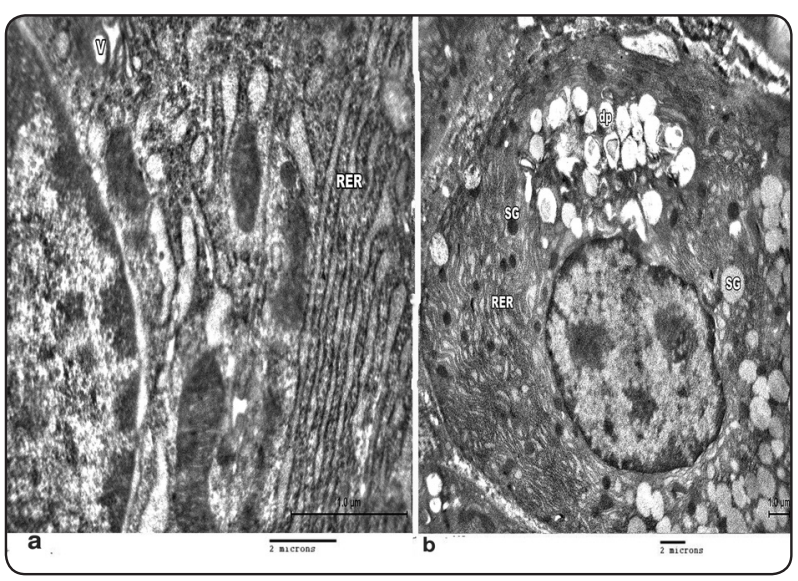

Fig. (4) (a). TEM 7 days after stoppage of the treatment shows expanded rough endoplasmic reticulum (RER), and cytoplasmic vacuoles (V).(b): TEM 7 days after stoppage of the treatment shows dense materials inside secretory granules (dp), different maturation of secretory granules (SG), and irregular rough endoplasmic reticulum (RER).

\section{DISCUSSION}

The efficacy of the non-selective $\beta$ agonist isoproterenol on salivary glands has been shown by several researches. There is general agreement that gland enlargement observed in salivary gland after administration of isoproterenol is caused by hyperplasia and hypertrophy ${ }^{(14,15)}$. Chronic administration of isoproterenol was found to be associated with excessive activation of protein synthesis, enlargement of acinar cells, hyperplasia, and salivary gland enlargement in both human and rat $^{(15,16)}$.

In this study, in Salb group, the integrity of the desmosomes was preserved, however, there were dense areas of chromatin at the periphery of the nucleus and dilatation of RER. These results come in agreement with the results of several studies. Takahashi study has shown that RER expansion is associated with the cellular status that precedes apoptosis ${ }^{(17)}$. Another study showed the treatment of human embryonic kidney 293 cell line expressing exogenous $B 2$ adrenergic receptors with salb for one day induced cell chromatin condensation ${ }^{(18)}$. Burniston et $\mathrm{al}^{(19)}$ has found that the administration of B2 AR agonist inducing apoptosis of the skeletal and cardiac muscles at low and high doses. In this study, the absence of the characteristic features of apoptosis except dilatation of RER may be due to the short period of Salb treatment.

In addition, salb group showed cytoplasmic vacuoles. Marked vocalization was shown in the cytoplasm of the acinar cells of rats feeding on a fluid diet ${ }^{(20)}$ and other researchers detect lipids in atrophic acinar cells ${ }^{(8)}$. Moreover, the ultrastructure of irradiated salivary gland showed the presence of intracytoplasmic vacuoles and fusion of several secretory granules ${ }^{(21)}$.

However, in this study, it was found that salb has a destructive effect on parotid acinar cells. Another study found that pretreated rats with isoproterenol, pilocarpine and methacholine showed less cytoplasmic vacuoles in irradiated salivary tissues. The protection of cell against loss of function induced by pretreatments with $\beta$-AR agonists may be caused by isoproterenol ( $\beta$-AR agonist) protection against loss of $\alpha 1-\mathrm{AR}$ and M3acetyl choline receptor activities ${ }^{(22)}$.

Moreover, in experimental diabetic rats induced by streptozotocin, the parotid gland showed autophagic vacuole formation, lipid accumulation in acini, and decreased secretion of $\alpha$-amylase ${ }^{(23)}$. The decreased salivary secretion has been correlated with decreased $\beta$-adrenergic/muscarinic receptors, a defect in muscarinic-cholinergic receptors of acinar cells and/or loss of response to neurotransmitter in salivary glands ${ }^{(24,25)}$.

In this study, the cytoplasm contained granules of different electron densities and a few of them have an electron dense body. As secretory proteins distributed within different regions of secretory granules and dense regions correlate with $\alpha$-amylase formation ${ }^{(26)}$, it is likely that parotid glands of salb treated group have a modified protein profile and increased amylase. 
In the current study, RER presented some expanded portions with cisternae arranged irregularly. The cytoplasm contained granules of different electron densities and a few of them have an electron dense body. The lumen of the acini contained abundant microvilli and secretory materials. At 7 days after salb treatment, the nucleus was compressed toward the base of the cell. One week after stoppage of salb treatment, RER showed some expanded cisternae and dense bodies still seen inside some secretory vesicles with variations in the maturation of secretory granules. All of these features may indicate active secreting acinar cell by salb.

However, PRP was found to increase in rat parotid saliva after B1-adrenergic stimulation ${ }^{(27)}$. Butcher et al study showed that salb is considerably less effective than isoproterenol in stimulating amylase release from rat parotid gland in vitro $^{(28)}$. Other studies suggest that the synthesis and induction of cystatins in submandibular acinar cell and PRP in parotid acinar cell may be regulated by ß1-adrenergic stimulation ${ }^{(29,30)}$. Increased secretion observed in our research and results of other studies that showed the induction of PRP and cystatin of parotid salivary gland in animals treated with salb may be due to nonspecific interaction with $\beta 1$ receptors on parotid glands ${ }^{(31)}$.

On the other hand, Salb acts selectively on $B 2$ receptors and forms less amount of saliva with high protein concentration. Moreover, it reduces water reabsorption into a salivary gland duct, and therefore proteins difficulty passes the duct lining because they depend on the transepithelial water transport of these ducts; the end result of this is a decrease in the amount of secreted salivary protein concentration in saliva ${ }^{(5,32)}$.

In this study, there were different densities of secretory granules with some granules having dense bodies. Moreover, there was a retention of immature secretory granules in the acinar cells and compressed nucleus toward the cell wall. Similarly, Hand and
Oliver ${ }^{(33)}$ study found immature secretory granules retained in the acinar cells after isoproterenol. Secretagogue stimulation of exocrine glands has shown changes in size and rate of formation of secretory granules ${ }^{(34)}$. The presence of immature secretory granules may be explained by the effect of $\beta$ adrenergic agonist on the mechanisms that regulate exocytosis, as well as the processes of membrane retrieval and recycling ${ }^{(33)}$.

Sharoni et al. have shown that newly synthesized secretory protein, although present in an isolatable secretory granule fraction, are not immediately available for discharge from parotid acinar cells. The immature granules presumably fail to fuse with the luminal plasmalemma because their membranes lack a recognition factor, fusogen, or some other component essential for exocytosis. Thus, the membrane of the newly formed granule must "mature," as does its content ${ }^{(35)}$.

The RER controls the synthesis, modification, folding, and export of proteins. An imbalance between the requirement for protein synthesis and the ability to handle them leads to the aggregation of misfolded or unfolded proteins, which is called RER stress. The adaptive response induced by the unfolded protein started to restore normal RER function ${ }^{(36)}$. If there is prolonged or severe RER stress, the adaptive response induced by the unfolded protein response cannot eliminate the RER stress and so on a cell-death program is triggered to get rid of the damaged cell ${ }^{(37)}$.

\section{CONCLUSION}

In this study, it may be concluded that treatment with salbutamol drug causes ultrastructural changes of the parotid glands after short term treatment. Some changes still present even after one week from stoppage of treatment.

\section{Conflict of interest:}

The authors declare no conflict of interest. 


\section{REFERENCES}

1. Barnes PJ . Pathophysiology of allergic inflammation. Immunol Rev. 2011; 242(1): 31-50.

2. Fanta CH. Asthma. NEJM. 2009; 360: 1002-14.

3. Cates CJ, Lasserson TJ. Regular treatment with salmeterol and inhaled steroids for chronic asthma: serious adverse events. Cochrane Database Syst Rev. 2009; 7: (4): CD007695.

4. Nelson HS. Is there a problem with inhaled long-acting $\beta$-adrenergic agonists? J Allergy Clin Immunol. 2006; 117 : $3-16$.

5. Scully C. Drug effects on salivary glands: dry mouth. Oral Dis. 2003; 9: 165-76.

6. Gehret AU, Hinkle PM. Importance of regions outside the cytoplasmic tail of G-protein-coupled receptors for phosphorylation and dephosphorylation. Biochem. J. 2010; 428: 235-45.

7. Buchner A, Sreebny LM. Enlargement of salivary glands: review of the literature. Oral Surg. 1972; 24:209-22.

8. Hand AR, Ho B. Liquid-diet-induced alterations of rat parotid acinar cells studied by electron microscopy and enzyme cytochemistry. Archs Oral Biol. 1981; 26: 369-80.

9. Matsuura S, Moreira JE, Bedi GS, Hand AR. Quantitative immunocytochemistry of rat submandibular secretory proteins. J Dent. Res. 1989; 69 (Spec. Iss.) 239: 1048.

10. Kim SK, Jones TP, Cuzzort LM. Protein synthesis and amylase messenger RNA content in rat parotid salivary glands after total or partial stimulation with isoproterenol. Arch Oral Biol. 1989; 34: 895-901.

11. Hagen KGT, Balys MM, Tabak LA, Melvin JE. Analysis of isoproterenol-induced changes in parotid gland gene expression. Physiol Genomics 2002; 8: 107-14.

12. Esfandiari A, Yousofi AR, Naghib SM. Histological study of the effect of salbutamol on rat parotid salivary gland. J Anim Vet Adv. 2008; 7: 456-9.

13. Ryberg M, Johansson I. The effects of long-term treatment with salmeterol and salbutamol on the flow rate and composition of whole saliva in the rat. Archs Oral Biol. 1995; 40: 187-91.

14. Hand AR, Ho B. Mitosis and hypertrophy of intercalated duct cells and endothelial cells in the isoproterenol-treated rat parotid gland. J Dent Res. 1985; 64: 1031-38.
15. Chisholm DM, Adi MM. Cell proliferation and apoptosis in isoprenaline-induced sialosis in the rat submandibular glands. Int. J. Exp. Path. 1995; 76: 263-9.

16. Melvin JE, Nguyen HV, Nehrke K, Schreiner CM, Ten Hagen KG, Scott W. Targeted disruption of the Nhe1 gene fails to inhibit $\beta 1$-adrenergic receptor-induced parotid gland hypertrophy. Am J Physiol Gastrointest Liver Physiol. 2001; 280: 694-700.

17. Takahashi S, Nakamura S, Domon T, Yamamoto T, Wakita M. Active participation of apoptosis and mitosis in sublingual gland regeneration of the rat following release from duct ligation. J Mol Histol. 2005; 36:199-205.

18. Qian SHI, Yuanyuan HOU, Yang YANG, Gang BAI. Protective effects of glycyrrhizin against $\beta 2$-Adrenergic receptor agonist-induced receptor internalization and cell apoptosis. Biol. Pharm. Bull. 2011; 34(5): 609-17.

19. Burniston JG, Tan LB, Goldspink DF. beta2-adrenergic receptor stimulation in vivo induces apoptosis in the rat heart and soleus muscle. J Appl Physiol. 2005; 98: 1379-86.

20. Leali SC, Toledo OA, Bezerra ACB. Morphological alterations of the parotid gland of rats maintained on a liquid diet. Braz Dent J. 2003; 14 (3): 172-6.

21. El- Batouti AA. Histological and ultrastructural evaluation of the protective effect of ginseng on gamma-irradiated rats' salivary Glands. Nature and Science 2013; 11(8): 114-21.

22. Coppes RP, Zeilstra LJW, Kampinga HH, Konings AWT. Early to late sparing of radiation damage to the parotid gland by adrenergic and muscarinic receptor agonists. British Journal of Cancer 2001; 85(7): 1055-63.

23. Mednieks MI, Szczepanski A, Clark B, Hand AR. Protein expression in salivary glands of rats with streptozotocin diabetes. Int J Exp Pathol. 2009; 90: 412-22.

24. Yamamoto H, Ishibashi K, Nakagawa Y, Maeda N, Zeng T, Robinson CP, Oxford GE, Chegini N, Humphreys-Beher MG. Detection of alterations in the levels of neuropeptides and salivary gland responses in the non-obese diabetic mouse model for autoimmune sialoadenitis. Scand J Immunol. 1997; 45: 55-61.

25. Fedirko NV, Kruglikov IA, Kopach OV, Vats JA, Kostyuk PG, Voitenko NV. Changes in functioning of rat submandibular salivary gland under streptozotocininduced diabetes are associated with alterations of $\mathrm{Ca} 2+$ signaling and $\mathrm{Ca} 2+$ transporting pumps. Biochemica et Biophysica Acta. 2006; 1762:294-303. 
26. Piras M, Hand AR, Mednieks MI, Piludu M. Amylase and cyclic amp receptor protein expression in human diabetic parotid glands. J Oral Pathol Med. 2010; 39: 715-21.

27. Johnson DA, Cortez JE. Chronic treatment with beta adrenergic agonists and antagonists alters the composition of proteins in rat parotid saliva. J. Dent. Res. 1988; 67: 1103-8.

28. Butcher FR, Goldman JA, Nemerovski M. Effect of adrenergic agents on $\alpha$ amylase release and adenosine 3',5'-monophosphate accumulation in rat parotid slices. Biochim. biophys. Acta (Amst.) 1975; 392: 82-94.

29. Matsuura S, Suzuki K. Immunohistochemical analysis of DNA synthesis during chronic stimulation with isoproterenol in mouse submandibular gland. J Histochem Cytochem. 1997; 45: 1137-45.

30. Cohen RE, Bedi GS, Neiders ME. Tissue distribution of an inducible cystatin in isoproterenol-treated rats. Lab. Invest. 1990.; 62: 452-8.

31. Bedi GS . The Effect of adrenergic agonists and antagonists on the expression of proteins in rat submandibular and parotid glands. Critical Reviews in Oral Biology and Medicine 1993; 4: 565-71.

32. Ryberg M, Moller C, Ericson T. Saliva composition and caries development in asthmatic patients with Beta 2 adrenoceptor agonists: a 4-Year follow up study. Scand J Dent Res. 1991; 99(3): 212-8.

33. Hand AR, Oliver C. Effects of secretory stimulation on the golgi apparatus and GERL of at parotid acinar cells. J Histochem Cytochem. 1984; 32(4): 403-12.

34. Nevalainen TJ, Janigan DT. Pilocarpine stimulation of exocrine pancreas secretion in vitro. $1974 ; 162(2): 161-7$

35. Sharoni Y, Eimerl S, Schramm M. Secretion of old versus new exportable protein in rat parotid slices. Control by neurotransmitters. J Cell Biol. 1976; 71: 107-22.

36. Ron D, Walter P. Signal integration in the endoplasmic reticulum unfolded protein response. Nat Rev Mol Cell Biol. 2007; 8: 519-29.

37. Sano R, Reed JC. ER stress-induced cell death mechanisms. Biochim Biophys Acta. 2013; 1833: 3460-70. 